\title{
Brain White Matter Hyperintensity Changes Associated with Vascular Cognitive Impairment and Dementia, Alzheimer's Dementia and Normal Aging
}

\author{
Vasküler Kognitif Bozukluk ve Demans, Alzheimer Demans ve Normal Yaşlanma ile İlişkili Beyin \\ Beyaz Cevher Hiperintensite Değişiklikleri
}

\section{Ayfer ERTEKIN \\ (D) 0000-0002-4313-2826}

Department of Neurology, Private Siirt Hayat Hospital, Siirt, Turkey

\begin{abstract}
Aim: The aim of this study was to analyze the relationship between the distribution and grading of white matter hyperintensity (WMH) obtained by brain magnetic resonance imaging and cognitive impairment associated with vascular cognitive impairment and dementia (VCID), Alzheimer's dementia (AD) and normal aging in individuals aged 65 years and older.

Material and Methods: Retrospective analysis was performed on a total of 372 patients, who met the criteria for AD, VCID and normal aging. The basic clinical criteria of DSM-V and NIA-AA were considered for AD. The DSM-V and NINDS-AIREN diagnostic criteria were used for VCID and probable vascular dementia (VaD). WMHs were graded according to the Fazekas criteria.

Results: Normal aging was detected in $58.3 \%(n=217)$ of the patients, AD in $24.7 \%(n=92)$ and VCID in $16.9 \%(n=63)$. The relationship between WMH and dementia was significant. $(\mathrm{p}<0.001)$. Periventricular hyperintensity was detected as $76.2 \%(n=70)$ in $\mathrm{AD}, 95.2 \%(\mathrm{n}=60)$ in VCID, $40.6 \%(n=88)$ in normal aging, and deep white matter hyperintensity was detected as $63.0 \%(n=58)$ in AD, $74.5 \%(n=47)$ in VCID, $44.2 \%(n=96)$ in normal aging. In the VCID group, $52.4 \%(n=33)$ had basal ganglia lesions and $60.3 \%(n=38)$ had classical infarct areas. No relationship was found between the presence of cortical lesion and cognition.

Conclusion: This study is important in terms of showing that it would be better to focus on markers of brain damage and dementia, such as WMH rather than focusing on clinical diagnoses with mixed-type pathologies such as Alzheimer's disease or vascular cognitive impairment.
\end{abstract}

Keywords: Alzheimer's dementia; vascular cognitive impairment, brain MRI; white matter hyperintensity.

\section{ÖZ}

Amaç: Bu çalışmanın amacı, 65 yaş ve üstü bireylerde, beyin manyetik rezonans görüntüleme (MRG) ile elde edilen beyaz madde hiperintensitesinin (white matter hyperintensity, WMH) dağılımı ve derecelendirmesi ile vasküler kognitif bozukluk ve demans (VCID), Alzheimer demans (AD) ve normal yaşlanma ile ilişkili kognitif etkilenme arasındaki ilişkiyi analiz etmektir.

Gereç ve Yöntemler: AD, VCID ve normal yaşlanma kriterlerine uygun toplam 372 hasta ile geriye dönük analiz yapıldı. AD için DSM-V ve 2011 NIA-AA temel klinik kriterleri dikkate alındı. VCID ve olası vasküler demans (VaD) için DSM-V ve NINDS-AIREN tanı kriterleri kullanıldı. WMH'ler Fazekas kriterlerine göre derecelendirildi.

Bulgular: Katılımcıların \%58,3'ünde (n=217) normal yaşlanma, \%24,7'sinde $(n=92)$ AD ve $\% 16,9$ 'unda (n=63) VCID tespit edildi. WMH ile demans arasındaki ilişki anlamlı idi $(\mathrm{p}<0.001)$. Periventriküler hiperintensite AD'de \%76,2 ( $\mathrm{n}=70)$, VCID'de \%95,2 ( $\mathrm{n}=60)$, normal yaşlanmada \%40,6 $(\mathrm{n}=88)$ olarak tespit edildi ve derin beyaz madde hiperintensitesi ise AD'de \%63,0 ( $\mathrm{n}=58)$, VCID'de \%74,5 $(\mathrm{n}=47)$, normal yaşlanmada \%44,2 $(\mathrm{n}=96)$ olarak saptand1. VCID grubunda \%52,4 $(\mathrm{n}=33)$ ile bazal ganglion lezyonları ve \%60,3 $(\mathrm{n}=38)$ ile klasik enfarkt alanları mevcuttu. Kortikal lezyon varlığı ile kognisyon arasındaki ilişki tespit edilmedi.

Sonuç: Bu çalışma Alzheimer hastalığı veya vasküler bilişsel bozukluk gibi mix tip patolojileri olan klinik tanılara odaklanmak yerine, belki de WMH gibi beyin hasarı ve demans belirteçlerine odaklanmanın daha iyi olacağını göstermesi açısından önemlidir.

Anahtar kelimeler: Alzheimer demans; vasküler kognitif bozulma, beyin MRG; white matter hiperintensite. 


\section{INTRODUCTION}

In cross-sectional and dimensional studies, there is strong evidence that white matter hyperintensities (WMHs) are clinically important markers of risk of stroke, dementia, death, depression, gait disturbance, and limitation of movement. In 22-dimensional meta-analysis studies, it has been reported that $\mathrm{WMH}$ is associated with a 2 -fold increase in the risk of progressive cognitive impairment, dementia, and 3-fold increase in the risk of stroke (1). In the general population, the proportion of WMHs range from $11 \%$ to $21 \%$ in 64-year-old adults and rises to $94 \%$ by the age of 82 . Female tend to have a higher number of WMH than male (2). In the study of Sachdev et al. (2), it was determined that $87 \%$ of the participants aged $60-70$ had subcortical, $68 \%$ had periventricular WMHs, $100 \%$ of the participants aged 80-90 had subcortical and 95\% had periventricular WMHs.

WMHs occur in many forms, each with a different combination of pathologies. Punctate WMHs, for example, are associated with myelin destruction, gliosis, and increased perivascular spaces, whereas large and confluent WMHs show some degree of myelin loss, axonal disruption, and more advanced pathological changes, including astrogliosis $(3,4)$. Kim et al. (5) have suggested that fiber tract damage distribution pattern is more associated with cognitive and motor impairment when evaluated with total WMH load.

The risk of dementia is greater when vascular comorbid conditions occur. The study of Bejot et al. (6) showed that the prevalence of vascular risk factors such as hypertension (HT), diabetes, atrial fibrillation, previous myocardial infarction, and transient ischemic attack history is higher in patients with post-stroke dementia. Available data show that cerebrovascular disease (CVD) significantly increases the risk of developing dementia disorders such as Alzheimer's dementia (AD) and vascular cognitive impairment and dementia (VCID) (7).

In this study, we analyzed both the hypothesis that WMHs are associated with cognitive impairment and its severity in older individuals with AD and VCID and the distribution of $\mathrm{WMH}$ in individuals with normal aging without middle-to-old age cognitive impairment. In the mild cognitively impaired and/or normal aging group, the prediction was made that 'WMHs may constitute a potentially useful marker for the identification of new risk factors for dementia'. This will provide important opportunities to recognize the early stages that lead to the development of WMH, prevent (or even reverse) brain damage in the early stages, and improve cognitive, physical, stroke, and dementia outcomes.

\section{MATERIAL AND METHODS}

\section{Study Design and Participants}

This study was conducted on the data obtained from the hospital data recording system and the ministry of health e-nabiz application, by retrospectively scanning a total of 372 patients aged 65 and over, who applied to the neurology outpatient clinic of Siirt Private Life Hospital between 2019 and 2021, who were eligible for AD, VCID and normal aging criteria. Consent was obtained for the study with the decision no:2021/02.04 dated 12.03.2021 and numbered 6264, at the meeting of the ethics committee of Siirt University non-interventional clinical research.
The patients' registered and diagnosed sociodemographic information, systemic diseases, HT, diabetes, chronic ischemic heart disease, atrial fibrillation, hyperlipidemia, history of stroke $\geq 12$ weeks were analyzed through the system.

Detailed biochemical blood parameters of the patients, especially B12, TSH, fT3, fT4, hemogram, liver and, kidney function tests, were examined. Diseases that may cause secondary cognitive impairment such as hypothyroidism, B12 deficiency, acute vascular damage, electrolyte imbalance (hyponatremia or hypernatremia, hypomagnesemia, hypercalcemia and hypocalcemia, hypoglycemia or hyperglycemia, anemia, uremia, and hepatic dysfunction), chronic systemic inflammatory diseases or diagnosed autoimmune disease and psychiatric disorders such as schizophrenia with neoplastic processes and which may cause cognitive impairment were excluded from the study. Anamnesis, physical and detailed neurological examination, electroencephalography (EEG), neuropsychological test results, neuroimaging details, and radiology comments were examined in detail. Cognitive evaluation is made in our clinic by applying the Mini-Mental State Examination (MMSE) test and Blessed Orientation-Memory-Concentration (BOMC) test performed by a specialist psychologist. In cognitive fields, a neuropsychological test battery was used, including memory functions (short and long-term memory), abstract thinking, judgment, aphasia, apraxia, agnosia and structural difficulty, visuospatial and structural functions.

Intima-Media Thickness (IMT) and Carotid Doppler Ultrasonography (USG) Evaluation

Detailed carotid Doppler USG reports of all patients participating in the study were examined. The standard position applied by the radiologist of our hospital was as follows; distant and proximal walls of arterial segments (common carotids, bifurcation and internal carotid arteries) are evaluated with Doppler ultrasound (7.5-10.0 MHz probe, Toshiba Aplio 300) device with patients in supine position, head turned and neck motionless. A standardized protocol is used for image analysis in B mode. The measurement of IMT measured in B-mode is from a plaque-free region with a clearly defined double line pattern. For carotid IMT measurement, a $1 \mathrm{~cm}$ segment is determined within the first $2 \mathrm{~cm}$ proximal region from the common carotid artery bulb. In this plaque-free region, measurements are made between the luminal and media-adventitia interfaces of the carotid artery, and the measurements are reported. In measurements made from bilateral common carotid arteries, an IMT value $\geq 1 \mathrm{~mm}$ is considered pathological. IMT $\geq 1.5 \mathrm{~mm}$ and above is considered as plaque. The degree of stenosis determined by gray scale and color Doppler USG is categorized as normal (no stenosis) $<50 \%$ stenosis, $50-69 \%$ as stenosis, and $\geq 70 \%$ stenosis, total or near occlusion and thrombus.

Diagnostic Criteria for Alzheimer's Dementia (AD) and Vascular Cognitive Impairment and Dementia (VCID) Patients were classified into three groups: AD, VCID (including multi-infarct dementia, strategic infarct dementia, and subcortical vascular encephalopathy), and normal aging. 
Dementia diagnosis according to 2013 Diagnostic and Statistical Manual of Mental Disorders, Fifth Edition (DSM-V) criteria; as evidence of significant decline from the previous level of performance in one or more cognitive domains (complex attention, executive function, learning, and memory, language, motor or social cognitive domain); A. A significant decline in cognitive function of the individual that a knowledgeable informant or clinician notices.

B.1. Cognitive performance deteriorates significantly, it is documented by another quantitative clinical assessment, preferably in the presence standardized neuropsychological tests or absence of them.

B.2. Cognitive impairments prevent independence in daily activities (need help in functional activities of daily life)

B.3. Cognitive impairments do not occur solely in the context of delirium.

B.4. Cognitive impairments are not better explained by another mental disorder. Specify:

* Without behavioral disorder: The cognitive disturbance is not accompanied by any clinically significant behavioral disturbances.

* With behavioral disorder (specify the disorder): If the cognitive disorder is accompanied by a clinically significant behavioral disorder (for example, psychotic symptoms, aggression, apathy, or other behavioral symptoms). For example, basic clinical criteria of major depressive disorder or schizophrenia (8).

Alzheimer's Dementia (AD)

AD criteria for DSM-V and 2011 National Institute on Aging and Alzheimer's Association (NIA-AA) and basic clinical criteria for probable AD were considered (9). According to DSM-V, for the diagnosis of major neurocognitive disorder due to $\mathrm{AD}$, impairment in at least two cognitive domains, one of which is learning and memory is required. For mild neurocognitive impairment due to $\mathrm{AD}$, insidious onset and progressive progression, as well as learning and memory deficits, are sufficient for diagnosis.

Vascular Cognitive Impairment and Dementia (VCID) DSM-V and National Institute of Neurological Disorders and Stroke - Association Internationale pour la Recherche et l'Enseignement en Neurosciences (NINDS-AIREN) diagnostic criteria were used for VCID and probable vascular dementia $(\mathrm{VaD})$. After diagnosis of mild and major neurocognitive disorder according to DSM-V diagnostic criteria, DSM-V should focus on CVD for VCID.

There should be evidence of damage supporting small vessel disease (SVD), including clinical features, significant impairment in frontal-executive function, and physical signs consistent with stroke or SVD, such as hemiparesis, pseudobulbar palsy, and visual field defects; neuroimaging evidence such as multiple lacunar infarctions or large and confluent white matter lesions. The NINDS-AIREN criteria must include at least one of the following focal neurologic symptoms: hemianopia, central facial weakness, dysarthria, motor or sensory hemisyndrome, hemiplegic gait or positive Babinski sign (10).

\section{Normal Aging}

In normal aging, individuals often retain long-standing personality traits and interests, including levels of initiative, motivation, sociability, empathy, influence, and behavior.
Vascular cognitive impairment (VCI) covers all cognitive impairments associated with CVD, from mild cognitive impairment to dementia. Simply put, VCI is a syndrome with clinical signs of a stroke or subclinical vascular brain injury and cognitive impairment affecting at least one cognitive domain. The most severe form of VCI is VaD.

Brain Magnetic Resonance Imaging (MRI) / Magnetic Resonance (MR) Angiography Evaluation and White Matter Hyperintensities (WMHs) FAZEKAS Classification

Brain MRI, MR angiography, and diffusion MRI were performed in a unit with 1.5 Tesla field strength. White matter lesions were evaluated on T2-weighted or Flair MR images. Classification was made for periventricular hyperintensity $(\mathrm{PVH})$ and deep white matter hyperintensity (DWMH) according to the following criteria $(11,12)$.

PVH was graded from 0 to 3 (11):

Grade 0, no lesion (Figure 1a); grade 1, in the form of a line or a cap (Figure 1b); grade 2, irregular hyperintensity and/or smooth halo (Figure 1c); and grade 3 lesion spreading to the periventricular region and deep white matter (Figure 1d).

DWMH was also graded from 0 to 3 (12):

Grade 0, no lesion (Figure 2a); grade 1, in the form of punctate (Figure 2b); grade 2, punctate hyperintensity prone to fusion (Figure 2c); grade 3, large confluent and enlarged punctate hyperintensity (Figure 2d).

White matter lesions were considered periventricular if the lesions were orginated from a location directly adjacent to the ventricules. If the lesions had no direct connection to the ventricules, or secondarily connected to the ventricles, they were considered to be located in the deep white matter lesions.

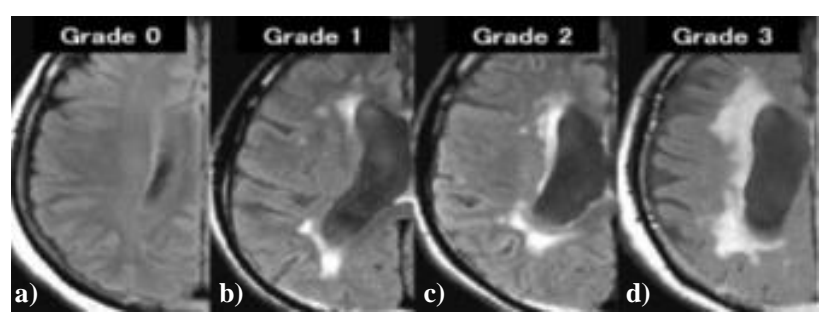

Figure 1. Periventricular hyperintensity $(\mathrm{PVH})$ grading of magnetic resonance images (11), a) grade 0, no lesion, b) grade 1 , in the form of a line or a cap, c) grade 2, irregular hyperintensity and/or smooth halo, d) grade 3, lesion spreading to the periventricular region and deep white matter

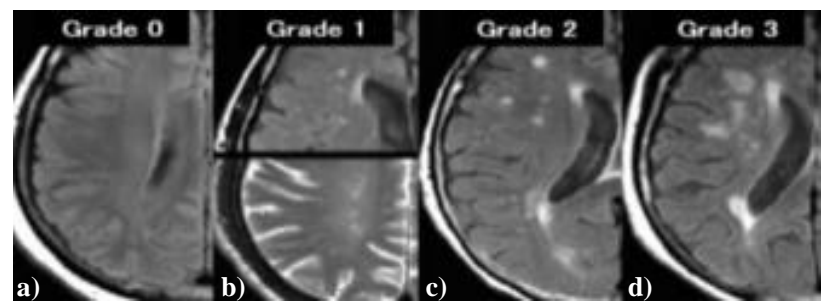

Figure 2. Deep white matter hyperintensity (DWMH) grading of magnetic resonance images $(12)$, a) grade 0 , no lesion, b) grade 1 , in the form of punctate, c) grade 2 , punctate hyperintensity prone to fusion, d) grade 3 , large confluent and enlarged punctate hyperintensity 
Radiological examinations were performed on retrospective radiology reports and images. Our hospital radiology reports are systematically transferred to the system by the radiologist on a daily basis. Brain neuroimaging reports are reported in detail such as periventricular and/or deep white matter lesions, subcortical lesions, basal ganglia lesions, incidental findings, encephalomalacia area, lacunae infarct in our radiology clinic. In our study, periventicular and deep white matter lesions were differentiated by reference to the radiology reports registered in the system, and brain MR images were opened one by one with the hospital picture archiving and communication system (PACS) and examined. WMH lesions were graded by the neurologist (author) according to references $(11,12)$.

\section{Statistical Analysis}

Statistical analyzes of the study were performed using Statistical Package for Social Sciences for Windows (IBM SPSS version 25.0, Armonk, NY, USA) software. The normality assumption of continuous variables was tested with Kolmogorov-Smirnov and Shapiro-Wilk tests. The descriptive statistics of the variables were given as mean \pm standard deviation, median (25th 75 th percentile), and $\mathrm{n}(\%)$, according to the variable type and the normality assumption. Chi-square tests, Fisher-Freeman-Halton exact test, and Mann-Whitney U, One-Way Analysis of Variance (ANOVA) tests were used for univariate analyzes of the variables in the study. Duncan multiple comparison test was used to compare the groups with a statistical difference as a result of analysis of variance. Cases with a p value below 0.05 in all statistical analyzes were interpreted as statistically significant.

\section{RESULTS}

A total of 372 patients took part in the research. Females made up $53.8 \%(n=200)$ of the participants, while males made up $46.2 \%(n=172)$. The participants' mean age was $76.02 \pm 7.87$ years. The normal aging group has $58.3 \%$ $(n=217)$ of the participants, $24.7 \%(n=92)$ have AD, and $16.9 \%(n=63)$ have VCID. Table 1 shows the correlations and explanatory statistics between the groups and factors that are the focus of the study.

In terms of the age variable, there was a statistically significant difference between the groups $(p<0.001)$. The mean age of the patients in the AD group (79.66 \pm 8.43$)$ was higher than the other groups. Gender and groups have a statistically significant relationship $(p=0.011)$. The proportion of female in the normal aging and VCID groups was higher than that of male, while the proportion of male in the AD group was higher than that of female. In patients with CVD $\geq 12$ weeks, the relationship between cognitive impairment and the VCID group was statistically significant $(\mathrm{p}<0.001)$. While $89.9 \%(\mathrm{n}=195)$ of patients in the normal aging group and $78.3 \%(n=72)$ of AD patients had no previous history of CVD, $61.9 \%(n=39)$ with VCID had a previous history of CVD $\geq 12$ weeks. $69.8 \%(n=44)$ of those in the VCID group had HT, while $30.2 \% \quad(n=19)$ did not $(p=0.064)$. There was no relationship between atrial fibrillation and cognitive impairment in this study. A significant relationship was found between IMT and the groups $(\mathrm{p}=0.001)$. In normal aging $32.7 \%(\mathrm{n}=71), 15.2 \%$ $(\mathrm{n}=14)$ in AD, and $15.9 \%(\mathrm{n}=10)$ in VCID, IMT $<1 \mathrm{~mm}$, while $84.8 \%(n=78)$ of AD patients and $84.1 \%(n=53)$ of
VCID patients, IMT $\geq 1 \mathrm{~mm}$. The relationship between plaque and its sub formations over $1.5 \mathrm{~mm}$ with normal aging and cognitive impairment was not found to be statistically significant $(\mathrm{p}=0.139)$. The relationship between left internal carotid artery (ICA) stenosis and groups was statistically significant $(\mathrm{p}=0.009) .18 .9 \%$ $(n=41)$ in normal aging, $31.5 \%(n=29)$ in $\mathrm{AD}$, and $33.3 \%$ $(n=21)$ in VCID group had left ICA stenosis $<50 \%$. No significant correlation was found with right ICA stenosis. PVH and the groups had a statistically significant relationship $(\mathrm{p}<0.001)$. PVH grade 0 was found in $59.4 \%$ $(n=129)$ with normal aging, $23.9 \%(n=22)$ of patients with $\mathrm{AD}$, and $4.8 \%(\mathrm{n}=3)$ with VCID. DWMH and the groups had a statistically significant relationship $(\mathrm{p}<0.001)$. While PVH was found in $76.2 \%(n=70)$ of AD patients and $95.2 \%(n=60)$ of VCID patients, DWMH was found in $63.0 \%(n=58)$ of AD patients and $74.5 \%(n=47)$ of VCID patients. PVH 40.6\% $(\mathrm{n}=88)$ and DWMH 44.2\% $(\mathrm{n}=96)$ were present in normal aging, but PVH 59.4\% $(n=129)$ and DWMH 55.8\% $(n=121)$ were absent. In brain MRI scans, the number of patients with classical infarcts matching a specific arterial irrigation area was lowest in the normal aging $(4.6 \%, n=10)$ group and highest in the VCID $(60.3 \%, n=38)$ group $(\mathrm{p}<0.001)$. The relationship between the absence of cortical lesions and the groups was statistically significant $(\mathrm{p}<0.001)$. The proportion of patients without cortical lesions in the normal aging group was $91.7 \%(n=199), 71.4 \%(n=45)$ in the VCID group, and $89.1 \%(n=82)$ in the AD group. The relationship between basal ganglia lesion and the groups were statistically significant $(\mathrm{p}<0.001)$. While the rate of those without basal ganglia lesions in the normal aging group was $94.0 \%$ $(n=204)$, this rate was $47.6 \%(n=30)$ in the VCID group. Basal ganglia lesions were prominent in the VCID group with a rate of $52.4 \%(n=33)$. The difference between the groups in terms of B12 values was not statistically significant $(\mathrm{p}=0.707)$.

A significant proportion of Alzheimer's patients had periventricular $(44.6 \%, n=41)$ extensive or irregular hyperintensity (grade 2) when compared with the normal aging group (13.8\%, $n=30)$, when VCID (46.0\%, $n=29)$ was compared with the normal aging $(2.3 \%, n=5)$ group, extensive PVH (grade 3) was found. Furthermore, 10.6\% $(n=23)$ DWMH was found in normal aging, $21.7 \%(n=20)$ in $\mathrm{AD}, 31.7 \%(\mathrm{n}=20)$ grade $2 \mathrm{DWMH}$ in the VCID group, and $19.0 \%(n=12)$ grade 3 DWMH in the VCID group.

\section{DISCUSSION}

White matter hyperintensities found on brain MRI were higher in AD and VCID patients than in the normal aging group, although periventricular and deep WMHs were significantly higher in the normal aging group, according to this study. Furthermore, the fact that the incidence of PVH and DWMH in brain MRI was similar in both groups suggested that periventricular and deep WMH could be part of the same disease. Moreover, contrary to what is known, the presence of white matter lesions in AD patients created a prediction for the question of what is the effect of white matter lesions on the background of $\mathrm{AD}$ classical neuropathology.

It was only recently discovered that neuroimagingidentified WMHs are associated with Alzheimer's disease. WMH affects the majority of adults over the age of 70 who 
Table 1. Explanatory statistics and comparisons of the groups

\begin{tabular}{|c|c|c|c|c|}
\hline & Normal Aging (n=217) & $\mathrm{AD}(\mathrm{n}=92)$ & $\operatorname{VCID}(n=63)$ & $\mathbf{p}$ \\
\hline Age (year), mean \pm SD & $74.34 \pm 7.41$ & $79.66 \pm 8.43$ & $76.48 \pm 6.82$ & $<0.001$ \\
\hline \multicolumn{5}{|l|}{ Gender, n (\%) } \\
\hline Female & $126(58.1)$ & $37(40.2)$ & $37(58.7)$ & \multirow{2}{*}{0.011} \\
\hline Male & $91(41.9)$ & $55(59.8)$ & $26(41.3)$ & \\
\hline Hypertension, n (\%) & $119(54.8)$ & $48(52.2)$ & $44(69.8)$ & 0.064 \\
\hline Diabetes, n (\%) & $55(25.3)$ & $23(25.0)$ & $25(39.7)$ & 0.065 \\
\hline Coronary Artery Disease, n (\%) & $58(26.7)$ & $31(33.7)$ & $13(20.6)$ & 0.189 \\
\hline Hyperlipidemia, n (\%) & $61(28.1)$ & $25(27.2)$ & $13(20.6)$ & 0.492 \\
\hline Past stroke ( $\geq \mathbf{1 2}$ weeks), n (\%) & $22(10.1)$ & $20(21.7)$ & $39(61.9)$ & $<0.001$ \\
\hline Atrial fibrillation, $\mathrm{n}(\%)$ & $31(14.3)$ & $24(26.1)$ & $14(22.2)$ & 0.036 \\
\hline \multicolumn{5}{|l|}{ Intima-media thickness, $\mathrm{n}(\%)$} \\
\hline Normal & $71(32.7)$ & $14(15.2)$ & $10(15.9)$ & \multirow{2}{*}{0.001} \\
\hline Pathological & $146(67.3)$ & $78(84.8)$ & $53(84.1)$ & \\
\hline \multicolumn{5}{|l|}{ Right ICA stenosis, n (\%) } \\
\hline None & $148(68.2)$ & $62(67.4)$ & $39(61.9)$ & \multirow{6}{*}{0.305} \\
\hline$<50$ & $56(25.8)$ & $20(21.7)$ & $16(25.4)$ & \\
\hline $50-69$ & $9(4.1)$ & $7(7.6)$ & $6(9.5)$ & \\
\hline$\geq 70$ & $3(1.4)$ & $1(1.1)$ & $1(1.6)$ & \\
\hline Total/near occlusion & $1(0.5)$ & $0(0.0)$ & $1(0.3)$ & \\
\hline Thrombus & $0(0.0)$ & $2(2.2)$ & $0(0.0)$ & \\
\hline \multicolumn{5}{|l|}{ Left ICA stenosis, n (\%) } \\
\hline None & $160(73.7)$ & $56(60.9)$ & $37(58.7)$ & \multirow{5}{*}{0.009} \\
\hline$<50$ & $41(18.9)$ & $29(31.5)$ & $21(33.3)$ & \\
\hline $50-69$ & $11(5.1)$ & $6(6.5)$ & $1(1.6)$ & \\
\hline$\geq 70$ & $5(2.3)$ & $0(0.0)$ & $3(4.8)$ & \\
\hline Total/near occlusion & $0(0.0)$ & $1(1.1)$ & $1(1.6)$ & \\
\hline \multicolumn{5}{|l|}{ Plaque structure, n (\%) } \\
\hline None & $85(39.2)$ & $22(23.9)$ & $16(25.4)$ & \multirow{4}{*}{0.139} \\
\hline Hypoechoic soft & $15(6.9)$ & $7(7.6)$ & $5(7.9)$ & \\
\hline Heterogeneous hypoechoic & $27(12.4)$ & $15(16.3)$ & $8(12.7)$ & \\
\hline Heterogeneous calcific/calcific & $90(41.5)$ & $48(52.2)$ & $34(54.0)$ & \\
\hline \multicolumn{5}{|l|}{ PVH, n (\%) } \\
\hline Grade 0 & $129(59.4)$ & $22(23.9)$ & $3(4.8)$ & \multirow{4}{*}{$<0.001$} \\
\hline Grade 1 & $53(24.4)$ & $10(10.9)$ & $6(9.5)$ & \\
\hline Grade 2 & $30(13.8)$ & $41(44.6)$ & $25(39.7)$ & \\
\hline Grade 3 & $5(2.3)$ & $19(20.7)$ & $29(46.0)$ & \\
\hline \multicolumn{5}{|l|}{ DWMH, n (\%) } \\
\hline Grade 0 & $121(55.8)$ & $34(37.0)$ & $16(25.4)$ & \multirow{4}{*}{$<0.001$} \\
\hline Grade 1 & $66(30.4)$ & $31(33.7)$ & $15(23.8)$ & \\
\hline Grade 2 & $23(10.6)$ & $20(21.7)$ & $20(31.7)$ & \\
\hline Grade 3 & $7(3.2)$ & $7(7.6)$ & $12(19.0)$ & \\
\hline Classical infarcts, $\mathrm{n}(\%)$ & $10(4.6)$ & $11(12.0)$ & $38(60.3)$ & $<0.001$ \\
\hline Basal ganglia lesions, n (\%) & $13(6.0)$ & $16(17.4)$ & $33(52.4)$ & $<0.001$ \\
\hline Cortical lesion, n (\%) & $18(8.3)$ & $10(10.9)$ & $18(28.6)$ & $<0.001$ \\
\hline B12, median (25th $\sim 75$ th percentile) & $304.0(222.0 \sim 384.5)$ & $283.0(196.2 \sim 382.0)$ & $310.0(200.0 \sim 494.0)$ & 0.707 \\
\hline
\end{tabular}

AD: Alzheimer's dementia, VCID: vascular cognitive impairment and dementia, ICA: internal carotid artery, PVH: periventricular hyperintensity, DWMH: deep white matter hyperintensity, SD: standard deviation

have been diagnosed with Alzheimer's disease (13). Alzheimer's disease is commonly referred to as a gray matter disease of the brain. However, recent neuroimaging studies have highlighted micro-and macrostructural abnormalities in white matter in the risk and progression of Alzheimer's disease, indicating that, in addition to neuronal loss, white matter degeneration and demyelination may be important pathophysiological features of the disease (14-16).

The Alzheimer's disease neuroimaging initiative cohort found a relationship between $\beta$-amyloid and WMHs in the brain in a recent study (16). The volume of WMH begins to increase 20 years before cognitive symptoms in patients with dominant $\mathrm{AD}$ mutations as $\beta$-amyloid and tau levels in the cerebrospinal fluid fluctuate (17). These findings further suggest that $\mathrm{AD}$ pathology may be related to vascular and/or nonvascular processes that result in WMHs, given that vascular disease is uncommon in patients with this young mutation $(18,19)$. In the other hand, cerebral amyloid angiopathy (CAA) in $\mathrm{AD}$ is a common age-related SVD characterized by amyloid- $\beta$ deposition in the walls of cortical arterioles and leptomeningeal vessels $(18,19)$. The majority of AD brains contain histological CAA to some degree. WMHs are 
caused by microvascular processes such as impaired perivascular clearance, plasma extravasation, inflammation, hypoperfusion, and endothelial dysfunction (18). In the brains of patients diagnosed with Alzheimer's disease, WMH severity was related to microinfarcts and a high burden of amyloid plaques (20). More likely, AD pathology (common in older people) and WMHs of vascular origin (even more common in older people) are often common, as noted in multiple autopsy-based studies of mixed pathologies (13). Depending on AD pathology, it is considered that some white matter lesions, especially in the late stages of the disease, occur secondary to Wallerian degeneration triggered by cortical neurodegenerative pathology (21).

Hypertension, insulin resistance, diabetes, obesity, hyperhomocysteinemia, and hyperlipidemia are all prevalent vascular risk factors in VCID and AD (22). Subclinical vascular brain injury and stroke cause $\mathrm{VaD}$, which is the most severe form of VCI (7). Post-stroke dementia risk is evaluated together with age and stroke lesion burden/location (severity, previous/recurrent stroke, dysphasia), pre-morbid markers of brain susceptibility/reserve (education level, pre-morbid addiction, leukoaraiosis severity), and basic cognitive score $(23,24)$.

There is strong evidence that middle age HT has a detrimental effect on cognitive function in old age, but the impact of old age HT on cognitive function is less clear. Observational studies have shown a cumulative effect of HT on cerebrovascular injury, but evidence from clinical trials that antihypertensive therapy improves cognitive function is inconclusive (25).

The number of patients with AD+/HT- in our study was similar to the number of patients without $\mathrm{AD}+/ \mathrm{HT}+$ (single and/or dual antihypertensive drugs were used). Patients with VCID+/HT+, on the other hand, had a significantly higher rate $(69.8 \%)$ than those with VCID+/HT-.

In people over the age of 65, type two diabetes mellitus (DM) is also a risk factor for cognitive impairment and dementia. Insulin resistance accelerates AD pathology (26). In a study by Abner et al. (27), it was found that DM increases brain infarctions, especially the number of lacunae, not on Alzheimer's pathology, that diabetes and infarction coexist with high levels of neuropathological changes in Alzheimer's disease compared to infarction and/or diabetes alone, and it is reported that it was associated with low MMTE scores. In our study, the incidence of DM was similar in normal aging, $\mathrm{AD}$, and VCID groups, and no significant difference was found between the groups.

Increased carotid intima-media thickness (CIMT) measured by USG is a surrogate marker of atherosclerosis and a strong predictor of future vascular events. This noninvasive and simply applicable marker has been reported to be associated with cognitive impairment.

Moon et al. (28) suggest that the elderly individuals with a larger CIMT have a higher future risk of progression to MCI or dementia; therefore, they might require a more intensive monitoring for the earlier detection of cognitive dysfunction. On the other hand, carotid artery stenosis, which causes an increase in the carotid pulse-flow rate, is a major risk factor for cerebral white matter disease $(29,30)$. It's associated with cognitive impairment and white matter damage (31). If global cerebral perfusion and heart disease induced by carotid artery stenosis/occlusion decrease below a critical threshold, they can impair cognitive function independently of brain lesions (32). This deterioration occurs with a $40-50 \%$ decrease in cerebral blood flow and suppression of brain activity and cognitive dysfunction (32). In our study, $61.9 \%$ of VCID patients had a history of stroke ( $\geq 12$ weeks). In the VCID and AD patient groups, the common carotid artery IMT was significant over $1 \mathrm{~mm}$, but no correlation was found between the structural formation of the plaque and cognitive impairment. It was observed that carotid stenosis was more common in AD and VCID patients compared to normal aging patients, and left carotid stenosis was more common in the AD and VCID groups, as a localization finding, compared to the right.

In recent years, the study of the causes of brain aging and dementia has shifted to cerebral white matter. Through vascular alterations such as arteriolar tortuous, reduced blood vessel fluidity, and venous collagenous, the white matter microvascular network contributes to the pathogenesis of WMH. A network of vessels "from the outside in" feeds the brain. The pial arteries, which branch off the main cerebral arteries on the brain's surface and penetrate the brain parenchyma (penetrating arteries), constitute a highly anastomotic network. The basal ganglia are supplied by penetrating vessels that originate directly from Willis and the proximal branches at the base of the brain. Unlike pial vessels and capillaries, penetrating vessels have several collateral branches, so the occlusion of a single vessel is sufficient to cause small ischemic lesions (lacuna infarctions) (33). In addition, deep subcortical white matter supplied by long penetrating arteries, whose perfusion pressure is predicted to be low, is considered to be particularly vulnerable to hemodynamic failure (34).

WMHs occur in many forms, each with a different combination of pathologies $(3,4)$. The disruption of oligodendrocyte precursor cells (35) or an impaired perivascular ("glymphatic") space are two possible explanations. Punctate WMHs, for example, are associated with myelin destruction, gliosis, and increased perivascular spaces, whereas large and confluent WMHs show some degree of myelin loss, axonal disruption, and more advanced pathological changes, including astrogliosis $(3,4)$. The parietal, temporal, and occipital lobes may be affected first, followed by the frontal lobe (36).

Dementia is associated with different vascular diseases (37). The neuropathology of VCID is heterogeneous and complex (38). The SVD occurs in the basal ganglia arteries and spreads to the peripheral white matter and leptomeningeal arteries, as well as the thalamic, cerebellar, and brainstem vessels, however, the neocortical vessels usually survive (39). Furthermore, pathogenic factors linked to oxidative stress and inflammation in cerebral vessels are considered to relate SVD pathology to neurovascular dysfunction and VCID (40). The number and size of macroscopic infarctions or large vessel disease appear to be related to an increased risk of dementia in clinical-pathological studies (41). As previously stated, studies in WMH have concentrated on demyelination 
and axonal loss, and the changes have been termed "ischemic" $(42,43)$. When demyelination and axonal destruction occur, the changes are permanent. Despite the fact that certain studies differentiate $\mathrm{PVH}$ from DWMH $(3,44)$, imaging studies show that periventricular and deep WMH are probably mostly part of a continuous disease $(44,45)$. A recent very large study in 2699 patients with stroke at 11 stroke centers in China created statistical maps of the WMH distribution and showed that periventricular and deep $\mathrm{WMH}$ is a continuation of a continuous pathology, and any significant difference in the distribution in some patients only reflects an earlier stage of disease (46). WMHs in brain MRI were shown to be considerably higher in the AD and VCID groups than in the normal aging group and were associated with cognitive impairment in this research. We found that periventricular and deep white matter lesions in brain MRI were seen at similar rates in dementia subtypes, and there was no significant difference in WMH distribution between VCID and $\mathrm{AD}$ groups. As in the literature example mentioned above (46), our study results suggested that PVH could not be evaluated differently from DWMH, and perhaps they could be lesions of different stages, intertwined with each other. We found that especially infarct areas matching the irrigation area of the great artery and strategically located lacunae and infarct areas with basal ganglia involvement were more common in VCID, and there was no relationship between cortical lesions and $\mathrm{WMH}$ and cognitive impairment. This study provides strong evidence that WMHs predict dementia risk and reveals vascular risk factors in their intrinsic dynamic.

\section{CONCLUSION}

Clinical investigations suggest that instead of focusing on mixed-type diseases like Alzheimer's disease or VCI it could be better to concentrate on markers that induce brain damage and dementia, like WMH. Currently, considering WMHs that are predicted to be of vascular origin and associated risk factors, it is certain that targeting vascular health throughout the life course as a prevention strategy will be effective in minimizing cognitive impairment in the middle and older age group and preventing and/or slowing the progression to dementia in the normal aging group.

Ethics Committee Approval: The study was approved by the Non-interventional Clinical Researches Ethics Committee of Siirt University (26.03.2021, 02.04).

Conflict of Interest: None declared by the authors.

Financial Disclosure: None declared by the authors.

Acknowledgements: I would like to thank Dr. Özkan Görgülü, Chairman of the Department of Biostatistics at Ahi Evran University, who created the table and statistics of this article and the radiologist Semih Sağlıklı, who wrote the brain neuroimaging reports.

Author Contributions: Idea/Concept: AE; Design: AE; Data Collection/Processing: AE; Analysis/Interpretation: AE; Literature Review: AE; Drafting/Writing: AE; Critical Review: AE.

\section{REFERENCES}

1. Debette S, Markus HS. The clinical importance of white matter hyperintensities on brain magnetic resonance imaging: systematic review and metaanalysis. BMJ. 2010;341:c3666.

2. Sachdev PS, Thalamuthu A, Mather KA, Ames D, Wright MJ, Wen W, et al. White matter hyperintensities are under strong genetic influence. Stroke. 2016;47(6):1422-8.

3. Gouw AA, Seewann A, van der Flier WM, Barkhof F, Rozemuller AM, Scheltens P, et al. Heterogeneity of small vessel disease: a systematic review of MRI and histopathology correlations. J Neurol Neurosurg Psychiatry. 2011;82(2):126-35.

4. Schmidt R, Schmidt H, Haybaeck J, Loitfelder M, Weis $\mathrm{S}$, Cavalieri M, et al. Heterogeneity in age-related white matter changes. Acta Neuropathol. 2011;122(2):171-85.

5. Kim SH, Park JS, Ahn HJ, Seo SW, Lee JM, Kim ST, et al. Voxel-based analysis of diffusion tensor imaging in patients with subcortical vascular cognitive impairment: correlates with cognitive and motor deficits. J Neuroimaging. 2011;21(4):317-24.

6. Béjot Y, Aboa-Eboulé C, Durier J, Rouaud O, Jacquin A, Ponavoy E, et al. Prevalence of early dementia after first-ever stroke: a 24-year population-based study. Stroke. 2011;42(3):607-12.

7. Gorelick PB, Scuteri A, Black SE, Decarli C, Greenberg SM, Iadecola C, et al. Vascular contributions to cognitive impairment and dementia: a statement for healthcare professionals from the American Heart Association/American Stroke Association. Stroke. 2011;42(9):2672-713.

8. Regier DA, Kuhl EA, Kupfer DJ. The DSM-5: Classification and criteria changes. World Psychiatry. 2013;12(2):92-8.

9. McKhann GM, Knopman DS, Chertkow H, Hyman BT, Jack CR Jr, Kawas CH, et al. The diagnosis of dementia due to Alzheimer's disease: recommendations from the National Institute on Aging-Alzheimer's Association workgroups on diagnostic guidelines for Alzheimer's disease. Alzheimers Dement. 2011;7(3):263-9.

10. Pohjasvaara T, Mäntylä R, Ylikoski R, Kaste M, Erkinjuntti T. Comparison of different clinical criteria (DSM-III, ADDTC, ICD-10, NINDS-AIREN, DSMIV) for the diagnosis of vascular dementia. National Institute of Neurological Disorders and StrokeAssociation Internationale pour la Recherche et l'Enseignement en Neurosciences. Stroke. 2000;31(12):2952-7.

11. Fazekas F, Chawluk JB, Alavi A, Hurtig HI, Zimmerman RA. MR signal abnormalities at $1.5 \mathrm{~T}$ in Alzheimer's dementia and normal aging. AJR Am J Roentgenol. 1987;149(2):351-6.

12. Senda J, Ito K, Kotake T, Kanamori M, Kishimoto H, Kadono I, et al. Association of leukoaraiosis with convalescent rehabilitation outcome in patients with ischemic stroke. Stroke. 2016;47(1):160-6.

13. Kapasi A, DeCarli C, Schneider JA. Impact of multiple pathologies on the threshold for clinically overt dementia. Acta Neuropathol. 2017;134(2):171-86.

14. Bartzokis G. Alzheimer's disease as homeostatic responses to agerelated myelin breakdown. Neurobiol Aging. 2011;32(8):1341-71. 
15. Matute C. Calcium dyshomeostasis in white matter pathology. Cell Calcium. 2010;47(2):150-7.

16. Marnane M, Al-Jawadi OO, Mortazavi S, Pogorzelec KJ, Wang BW, Feldman HH, et al. Periventricular hyperintensities are associated with elevated cerebral amyloid. Neurology. 2016;86(6):535-43.

17. Lee S, Viqar F, Zimmerman ME, Narkhede A, Tosto G, Benzinger TL, et al. White matter hyperintensities are a core feature of Alzheimer's disease: evidence from the dominantly inherited Alzheimer network. Ann Neurol. 2016;79(6):929-39.

18. Smith EE. Cerebral amyloid angiopathy as a cause of neurodegeneration. J Neurochem. 2018;144(5):651-8.

19. Roseborough A, Ramirez J, Black SE, Edwards JD. Associations between amyloid beta and white matter hyperintensities: a systematic review. Alzheimers Dement. 2017;13(10):1154-67.

20. Dallaire-Théroux C, Callahan BL, Potvin O, Saikali S, Duchesne S. Radiological- pathological correlation in Alzheimer's disease: systematic review antemortem magnetic resonance imaging findings. J Alzheimers Dis. 2017;57(2):575-601.

21. McAleese KE, Walker L, Graham S, Moya ELJ, Johnson M, Erskine D, et al. Parietal white matter lesions in Alzheimer's disease are associated with cortical neurodegenerative pathology, but not with small vessel disease. Acta Neuropathol. 2017;134(3):459-73.

22. Kalaria RN, Akinyemi R, Ihara M. Does vascular pathology contribute to Alzheimer changes? J Neurol Sci. 2012;322(1-2):141-7.

23. Pendlebury ST, Rothwell PM, Oxford Vascular Study. Incidence and prevalence of dementia associated with transient ischaemic attack and stroke: analysis of the population-based Oxford Vascular Study. Lancet Neurol. 2019;18(3):248-58.

24. Moulin S, Labreuche J, Bombois S, Rossi C, Boulouis $\mathrm{G}$, Hénon $\mathrm{H}$, et al. Dementia risk after spontaneous intracerebral haemorrhage: a prospective cohort study. Lancet Neurol. 2016;15(8):820-9.

25. Iadecola C, Yaffe K, Biller J, Bratzke LC, Faraci FM, Gorelick PB, et al. Impact of hypertension on cognitive function: a scientific statement from the American Heart Association. Hypertension. 2016;68(6):e67-94.

26. Umegaki H. Impaired glycemia and Alzheimer's disease. Neurobiol Aging. 2014;35(10):e21.

27. Abner EL, Nelson PT, Kryscio RJ, Schmitta FA, Fardo DW, Woltjer RL, et al. Diabetes is associated with cerebrovascular but not Alzheimer neuropathology. Alzheimers Dement. 2016;12(8):882-9.

28. Moon JH, Lim S, Han JW, Kim KM, Choi SH, Park $\mathrm{KS}$, et al. Carotid intima-media thickness is associated with the progression of cognitive impairment in older adults. Stroke. 2015;46(4):1024-30.

29. Kandiah N, Goh O, Mak E, Marmin M, Ng A. Carotid stenosis: a risk factor for cerebral white-matter disease. J Stroke Cerebrovasc Dis. 2014;23(1):136-9.

30. Baradaran H, Mtui EE, Richardson JE, Delgado D, Dunning A, Marshall RS, et al. White matter diffusion abnormalities in carotid artery disease: a systematic review and meta-analysis. $J$ Neuroimaging. 2016;26(5):481-8.
31. Ryberg C, Rostrup E, Paulson OB, Barkhof F, Scheltens P, van Straaten EC, et al. Corpus callosum atrophy as a predictor of age-related cognitive and motor impairment: a 3-year follow-up of the LADIS study cohort. J Neurol Sci. 2011;307(1-2):100-5.

32. Marshall RS. Effects of altered cerebral hemodynamics on cognitive function. $\mathrm{J}$ Alzheimers Dis. 2012;32(3):633-42.

33. Shih AY, Blinder P, Tsai PS, Friedman B, Stanley G, Lyden PD, et al. The smallest stroke: occlusion of one penetrating vessel leads to infarction and a cognitive deficit. Nat Neurosci. 2013;16(1):55-63.

34. Iadecola $\mathrm{C}$. The neurovascular unit coming of age: a journey through neurovascular coupling in health and disease. Neuron.2017;96(1):17-42.

35. Joutel A, Chabriat H. Pathogenesis of white matter changes in cerebral small vessel diseases: beyond vesselintrinsic mechanisms. Clin Sci. 2017;131(8):635-51.

36. Hase Y, Horsburgh K, Ihara M, Kalaria RN. White matter degeneration in vascular and other ageingrelated dementias. J Neurochem. 2018;144(5):617-33.

37. Kalaria RN, Akinyemi R, Ihara M. Stroke injury, cognitive impairment and vascular dementia. Biochim Biophys Acta. 2016;1862(5):915-25.

38. Arvanitakis Z, Capuano AW, Leurgans SE, Bennett DA, Schneider JA. Relation of cerebral vessel disease to Alzheimer's disease dementia and cognitive function in elderly people: a cross-sectional study. Lancet Neurol. 2016;15(9):934-43.

39. Thal DR, Grinberg LT, Attems J. Vascular dementia: different forms of vessel disorders contribute to the development of dementia in the elderly brain. Exp Gerontol. 2012;47(11):816-24.

40. Iadecola C. The pathobiology of vascular dementia. Neuron. 2013;80(4):844-66.

41. Schneider JA, Arvanitakis Z, Bang W, Bennett DA. Mixed brain pathologies account for most dementia cases in community-dwelling older persons. Neurology. 2007;69(24):2197-204.

42. Kalaria RN, Kenny RA, Ballard CG, Perry R, Ince P, Polvikoski T. Towards defining the neuropathological substrates of vascular dementia. J Neurol Sci. 2004;226(1-2):75-80.

43. Fernando MS, Simpson JE, Matthews F, Brayne C, Lewis CE, Barber R, et al. White matter lesions in an unselected cohort of the elderly: molecular pathology suggests origin from chronic hypoperfusion injury. Stroke. 2006;37(6):1391-8.

44. Valdés Hernández MC, Piper RJ, Bastin ME, Royle NA, Maniega SM, Aribisala BS, et al. Morphologic, distributional, volumetric, and intensity characterization of periventricular hyperintensities. AJNR Am J Neuroradiol. 2014;35(1):55-62.

45. Fazekas F. Incidental periventricular white matter hyperintensities revisited: what detailed morphologic image analyses can tell us. AJNR Am J Neuroradiol. 2014;35(1):63-4.

46. Ryu WS, Woo SH, Schellingerhout D, Chung MK, Kim CK, Jang MU, et al. Grading and interpretation of white matter hyperintensities using statistical maps. Stroke. 2014;45(12):3567-75. 